\title{
Propriedades funcionais das proteínas de amêndoas da faveleira (Cnidosculus phyllacanthus (Mart.) Pax. et K. Hoffm.) com e sem espinhos
}

\author{
Functional properties of the seed kernel proteins of faveleira plant with or without thorns
}

\author{
Mônica Tejo CAVALCANTI I*, Pushkar Singh BORA ${ }^{1}$, Juan Carlos Letelier CARVAJAL ${ }^{1,2}$
}

\begin{abstract}
Resumo
A faveleira possui amêndoas com potencial em óleos e proteínas alimentares e é encontrada em todos os estados do nordeste brasileiro, principalmente nas regiões do sertão e caatinga. Objetivando a sua aplicação em formulações alimentícias, as propriedades funcionais das proteínas de amêndoas da faveleira com espinhos (FCE), e sem espinhos (FSE) foram estudadas. As amêndoas apresentaram, elevado conteúdo de lipídio (40,56 e 40,21\%) e proteína (33,00 e 35,77\%) e depois de desengordurada, apresentou 57,55 e 63,00\% respectivamente. $\mathrm{Na}$ obtenção dos isolados proteicos, os índices em proteínas extraídas foram de 83,51\% para a FCE e 80,57\% para a FSE em pH 10,5. Os índices de proteínas recuperadas através da precipitação isoelétrica foram de 72,84 e $72,11 \%$ em pH 4,5. Os índices de proteínas solúveis e as propriedades de emulsificação mostraram-se dependentes do $\mathrm{pH}$, com valores mínimos no ponto isoelétrico e mais elevados em pH ácido e básico ao pI. O isolado proteico da FSE apresentou melhor capacidade de absorção de água e de óleo em relação à FCE. Quando avaliadas através da atividade e da estabilidade de emulsão os isolados apresentaram performance apropriada tanto na região ácida quanto alcalina do pI.
\end{abstract}

Palavras-chave: faveleira; proteínas; isolado proteico; propriedades funcionais.

\begin{abstract}
The seed kernel of faveleira plant is a potential source of edible oil and proteins. The plant grows in all the northeastern states of Brazil, mainlly in the sertão (backlands) and caatinga regions. With an objective of its use in food formulations, the functional properties of the protein isolates of the kernel from the faveleira plants with (FCE) or without thorns (FSE) were studied. The kernels presented high lipid (40.56 and $40.21 \%$ ) and protein (33.0 and 35.77\%) content which increased to about 57.55 and $63.0 \%$ respectively after the lipid removal. In the preparation of protein isolates, the content of protein extraction was $83.5 \%$ for FCE and $80.57 \%$ for FSE at pH 10.5 while the protein recovery through isoelectric precipitation at $\mathrm{pH} 4.5$ was 72.84 and $72.11 \%$, respectively. The protein solubility index and the emulsification properties presented $\mathrm{pH}$ dependence with minimum values at isoelectric $\mathrm{pH}$ and maximum value at the extreme acidic and basic $\mathrm{pHs}$. The protein isolate FSE showed better water and oil absorption capacities than FCE. The emulsion capacity and emulsion stability of both isolates presented appropriate performance in acidic and alkaline $\mathrm{pH}$.

Keywords: faveleira; protein; protein isolate; functional properties.
\end{abstract}

\section{Introdução}

O termo propriedade funcional é definido como toda propriedade não nutricional que influi no comportamento durante o processamento, estocagem e preparação, controla sua conveniência como ingrediente alimentar e influencia na aceitação e no consumo do produto final (ORDONEZ et al., 2005). As proteínas convencionais quando substituídas por proteínas vegetais deverão manter ou melhorar a qualidade e aceitabilidade dos produtos aos quais foram incorporadas (EL NASRI; EL TINAY, 2007).

A faveleira (Cnidosculus phyllacanthus (Mart.) Pax. et K. Hoffm.) é uma Euforbiácea xerófila arbórea que atinge cinco metros de altura e possui sementes ricas em óleo comestível (DUQUE, 1980). Os abundantes espinhos da faveleira nativa são causticantes e constitui um enorme empecilho a sua exploração (BRAGA, 1960). Entretanto, são encontrados naturalmente, com menor frequência, exemplares inermes (sem espinhos) em populações nativas (MOREIRA et al., 1974). Além desta variabilidade genética, o novo fenótipo encontrado também apresenta outras características que apresentam variações como folhas, frutos e flores.

A fim de contribuir para a preservação de espécies vegetais nativas da região do Semi-Árido do nordeste brasileiro, o presente trabalho tem como objetivo caracterizar algumas propriedades funcionais do isolado proteico das amêndoas da faveleira com e sem espinhos no que diz respeito à solubilidade, absorção de água e de óleo e propriedades emulsificantes, estabelecendo assim seu potencial de utilização como ingrediente funcional de produtos alimentícios para viabilizar seu aproveitamento na indústria de alimentos.

Recebido para publicação em 13/12/2007

Aceito para publicação em 4/1/2009 (003072)

Programa de Pós-graduação em Ciências e Tecnologia de Alimentos - CT, Universidade Federal da Paraíba - UFPB, Campus I, CEP 58059-900, João Pessoa - PB, Brasil,

E-mail: monicatejoc@yahoo.com.br

2 Departamento de Alimentos, Facultad de Recursos del Mar, Universidad de Antofagasta - Antofagasta, Chile

${ }^{*}$ A quem a correspondência deve ser enviada 


\section{Material e métodos}

\subsection{Matéria-prima}

As amêndoas da faveleira (Cnidoscolus phyllacanthus (Mart.) Pax et K. Hoffm.) utilizadas na obtenção dos isolados proteicos foram colhidas no município de Santa Luzia, Estado da Paraíba, Brasil. As sementes foram quebradas e suas amêndoas moídas em liquidificador doméstico. A farinha obtida foi peneirada em malha de 40 mesh e desengordurada com hexano em aparelho de soxhlet.

\subsection{Componentes centesimais}

A composição centesimal (umidade, cinzas, lipídios, proteínas) da farinha das amêndoas in natura da faveleira com e sem espinhos foi determinada conforme os procedimentos analíticos da AOAC (2000) e o conteúdo de carboidratos totais, incluindo fibras, foram calculados por diferença de 100 com a soma dos percentuais dos demais componentes da composição centesimal.

\subsection{Obtenção do isolado proteico}

O isolado proteico da amêndoa da faveleira com e sem espinhos foi adquirido a partir da farinha desengordurada, à qual se adicionou água destilada na proporção de 1:20, agitou-se por 2 horas e seu $\mathrm{pH}$ foi ajustado a 10,5 com hidróxido de sódio 1,0 M. O extrato obtido foi centrifugado por 30 minutos a $1.900 \times \mathrm{G}$ em centrifuga refrigerada e $\mathrm{o}$ resíduo extraído por mais duas vezes nas mesmas condições. Os sobrenadantes foram combinados, medindo-se o volume total e a concentração de proteína solúveis pelo método do biureto (GORNALL et al., 1949), usando-se como padrão a albumina bovina (Sigma chemical), e em seguida ajustou-se o pH a 4,5 com ácido clorídrico 1,0 M. Após precipitação, o extrato total foi centrifugado sob refrigeração a $1600 \times$ G por 30 minutos. As proteínas precipitadas isoeletricamente foram liofilizadas e então armazenadas em vidro sob refrigeração a $5{ }^{\circ} \mathrm{C}$ (McWATTERS; HOLMES, 1979).

\subsection{Propriedades funcionais das proteínas}

\section{Solubilidade}

A partir de uma suspensão contendo $0,25 \mathrm{~g}$ em proteínas em 25,0 mL de água destilada, determinou-se a solubilidade do isolado proteico, variando o $\mathrm{pH}$ de 2,0 a 11,0, conforme Dench, Rivas e Caygill (1981). As proteínas solúveis foram quantificadas pelo método do biureto (GORNALL et al., 1949).

\section{Absorção de água e óleo}

$\mathrm{Na}$ avaliação da absorção de água, amostras equivalentes a $0,25 \mathrm{~g}$ de proteínas foram misturadas individualmente em tubos de centrífuga com 2,5 mL de água destilada, agitou-se por 1 minuto e, após 30 minutos com agitações ocasionais, os tubos foram centrifugados a $2.750 \times \mathrm{G}$ durante 10 minutos. Os volumes sobrenadantes resultantes foram medidos e o resultado expresso em $\mathrm{mL}$ de água/g proteínas após a correção de proteínas solúveis (QUINN; PATON, 1979). Na absorção de óleo, 0,25 g em proteínas foram misturados em tubos com 2,5 mL de óleo de soja (SOYA, BUNGE ALIMENTOS S. A.), densidade de 0,922 g.mL $\mathrm{mL}^{-1}$ a $25^{\circ} \mathrm{C}$ e o resultado expresso em $\mathrm{mL}$ de óleo/g proteína seguindo a metodologia descrita por Lin e Zayas (1987).

\section{Capacidade de emulsificação}

Conforme o método de Weeb, Ivey e Cric (1970), Kato et al. (1985) e Hung e Zayas (1991), determinou-se a capacidade emulsificante a diferentes pHs $(2,0 ; 4,0 ; 6,0$ e 8,0) em amostra de 1,0 mg proteínas/mL água destilada, utilizando-se como parâmetro o aumento da resistência elétrica até a inversão da emulsão original óleo/água em água/óleo, detectada por um par de eletrodos. A emulsão foi agitada numa velocidade de $10.000 \mathrm{rpm}$ em temperatura ambiente $\left(28{ }^{\circ} \mathrm{C}\right)$, sendo adicionado óleo refinado de soja até o registro da resistência infinita do meio pelo multímetro. Para efeito de comparação, a capacidade de emulsificação da caseína bovina (Sigma chemical) foi determinada usando as mesmas condições experimentais.

\section{Atividade e estabilidade de emulsão}

A atividade e a estabilidade de emulsão foram determinadas de acordo com o método de Yasumatsu, Sawada e Moritaka (1972). Volumes de $20 \mathrm{~mL}$ de suspensão com 0,5 g de proteínas em $20 \mathrm{~mL}$ de água destilada foram agitados em temperatura ambiente em diferentes pHs (2,0, 4,0, 6,0 e 8,0), misturados com $20 \mathrm{~mL}$ de óleo refinado de soja, e a emulsão formada a $10.000 \mathrm{rpm}$ foi centrifugada. $\mathrm{O}$ resultado da atividade de emulsão foi expresso como percentual de emulsão formada no volume total e a estabilidade de emulsão foi determinada após aquecimento da emulsão formada a $80{ }^{\circ} \mathrm{C}$ por 30 minutos, resfriamento em gelo por 15 minutos e centrifugação a $1388 \times \mathrm{G}$ por 15 minutos. A estabilidade de emulsão foi calculada como sendo o percentual da atividade emulsificante que permaneceu emulsionado após sofrer tratamento térmico.

\subsection{Análise estatística}

Os resultados foram submetidos à análise estatística denominada " $t$ de Student" e os dados relativos às propriedades funcionais foram inicialmente avaliados por meio da Análise Estatística de Variância (ANOVA), com as diferenças significativas determinadas pelo teste de Tukey. Considerouse o nível de probabilidade de erro $(p)$ menor que $5 \%$ para determinar a significância em todos os testes, os quais foram efetuados através do programa SPSS for Windows - 11.0 (SPSS. INC, 2001).

\section{Resultados e discussão}

\subsection{Composição centesimal}

A riqueza em lipídios e proteínas é a razão maior das sementes oleaginosas terem vasta aplicação em sistemas alimentícios manufaturados ou de serem utilizadas diretamente 
na alimentação humana e animal. A Tabela 1 mostra a composição centesimal das amêndoas da faveleira com e sem espinhos.

As amêndoas da faveleira não apresentaram significância entre as duas variedades para a umidade e lipídio, porém para os demais componentes centesimais como proteína e cinza houve diferença significativa.

O óleo extraído das amêndoas da faveleira com e sem espinhos apresentou melhor rendimento que outras oleaginosas como o chichá $(22,5 \%)$ (OLIVEIRA et al., 2000) e a soja $(21,12 \%)$ (BARCELOS; VILAS BOAS; LIMA, 2002). Após o processo de recuperação do solvente, o óleo apresentou cor amarela clara e odor agradável. O óleo da faveleira tem boas características nutricionais, uma vez que contém 53,8\% de ácidos graxos saturados e $42,4 \%$ de ácidos graxos insaturados, com predominância do ácido linoleico (C18:2) de 41,6\% (SANTOS et al., 2005).

As amêndoas da faveleira apresentaram melhor rendimento proteico comparadas com outras amêndoas como girassol $(27,3 \%)$, amendoim $(27,6 \%)$, gergelim $(21,0 \%)$ (KHALIL et al., 1985), castanha de caju (22,1\%) (QUEIROGA NETO et al., 2001), castanha-do-pará (16,5\%; 14,29\%) (RAMOS; BORA, 2003; SOUZA; MENEZES, 2004) e apresentou-se inferior à soja (35,85\%) (BARCELOS; VILAS BOAS; LIMA, 2002).

\subsection{Rendimento do isolado proteico}

Os índices de rendimento na extração e na precipitação, verificados no processo de obtenção do isolado proteico de amêndoas das variedades da faveleira com e sem espinhos, constam na Tabela 2 .

A partir da farinha desengordurada, $83,51 \%$ das proteínas da faveleira com espinhos foram extraídas e 72,84\% foram precipitadas em relação ao conteúdo proteico da amostra inicial, e o precipitado recuperado por centrifugação resultou num isolado com $81,08 \%$ de proteína. Para a faveleira sem espinhos, $80,57 \%$ de proteínas foram extraídas e $72,11 \%$ foram precipitadas, e o precipitado recuperado resultou num isolado com $90,02 \%$ de proteína.

Os teores de proteínas solúveis nos isolados proteicos foram utilizados para o cálculo da quantidade de isolado a ser usado na determinação das propriedades funcionais.

Tabela 1. Composição centesimal das amêndoas da faveleira com (FCE) e sem espinhos (FSE).

\begin{tabular}{lcc}
\hline \multirow{2}{*}{$\begin{array}{c}\text { Componentes } \\
\text { centesimais (\%) }\end{array}$} & \multicolumn{2}{c}{ Amostras } \\
\cline { 2 - 3 } & $\begin{array}{c}\text { Faveleira com } \\
\text { espinhos (FCE) }\end{array}$ & $\begin{array}{c}\text { Faveleira sem } \\
\text { espinhos (FSE) }\end{array}$ \\
\hline Umidade & $4,27 \pm 0,07^{\mathrm{a}}$ & $4,36 \pm 0,19^{\mathrm{a}}$ \\
Proteína $(\mathrm{N} \times 6,25)$ & $33,00 \pm 0,74^{\mathrm{a}}$ & $35,77 \pm 0,63^{\mathrm{b}}$ \\
Lipídio & $40,56 \pm 0,80^{\mathrm{a}}$ & $40,21 \pm 0,56^{\mathrm{a}}$ \\
Cinza & $5,45 \pm 0,24^{\mathrm{a}}$ & $6,08 \pm 0,29^{\mathrm{b}}$ \\
Carboidrato $^{\star}$ & 16,72 & 13,58 \\
\hline
\end{tabular}

${ }^{*}$ Carboidratos por diferença ( 100 menos o somatório dos outros componentes). Resultados das análises com média de seis repetições ( \pm desvio padrão). Letras diferentes (na mesma linha) apresentaram diferença significativa $(\mathrm{p}<0,05)$ pelo teste de $t$-student.
Quando comparada a outras fontes proteicas vegetais a variedade com espinhos $(83,51 \%)$ e a sem espinhos $(80,57 \%)$ apresentaram rendimento proteico aproximado ao da castanha de caju (78,80\%) (QUEIROGA NETO et al., 2001), da castanhado-pará (81,30\%) (RAMOS; BORA, 2003) e da macadâmia (83,00\%) em pH de extração 12 (BORA; RIBEIRO, 2004).

\subsection{Propriedades funcionais}

\section{Solubilidade}

Observa-se na Figura 1, que os isolados apresentaram solubilidade mínima no $\mathrm{pH}$ 4,0 (ponto isoelétrico) e máxima, consecutivamente, em pHs 2,0 e 10,0. Os isolados proteicos

Tabela 2. Extração e recuperação de proteínas na obtenção do isolado proteico de $100 \mathrm{~g}$ da farinha desengordurada das amêndoas das variedades FCE e FSE.

\begin{tabular}{lrrrr}
\hline & \multicolumn{4}{c}{ Proteína } \\
\cline { 2 - 5 } & \multicolumn{2}{c}{ FCE } & \multicolumn{2}{c}{ FSE } \\
\cline { 2 - 5 } & Massa $(\mathrm{g})$ & $\%$ & Massa $(\mathrm{g})$ & \multicolumn{1}{c}{$\%$} \\
\hline Proteína total na farinha & $57,55 \pm 0,75$ & 100 & $63,00 \pm 0,47$ & 100 \\
desengordurada $(\mathrm{N} \times 6,25)$ & & & & \\
Proteína extraída & $48,06 \pm 0,32$ & 83,51 & $50,76 \pm 0,53$ & 80,57 \\
Precipitação Isoelétrica & $41,92 \pm 0,27$ & 72,84 & $45,43 \pm 1,09$ & 72,11 \\
Proteína não precipitada & $6,14 \pm 0,59$ & 10,67 & $5,34 \pm 0,64$ & 8,48 \\
Proteína não extraída & $9,49 \pm 0,32$ & 16,49 & $15,70 \pm 0,53$ & 24,92 \\
\hline Rey
\end{tabular}

Resultado das análises com média de três repetições ( \pm desvio padrão).

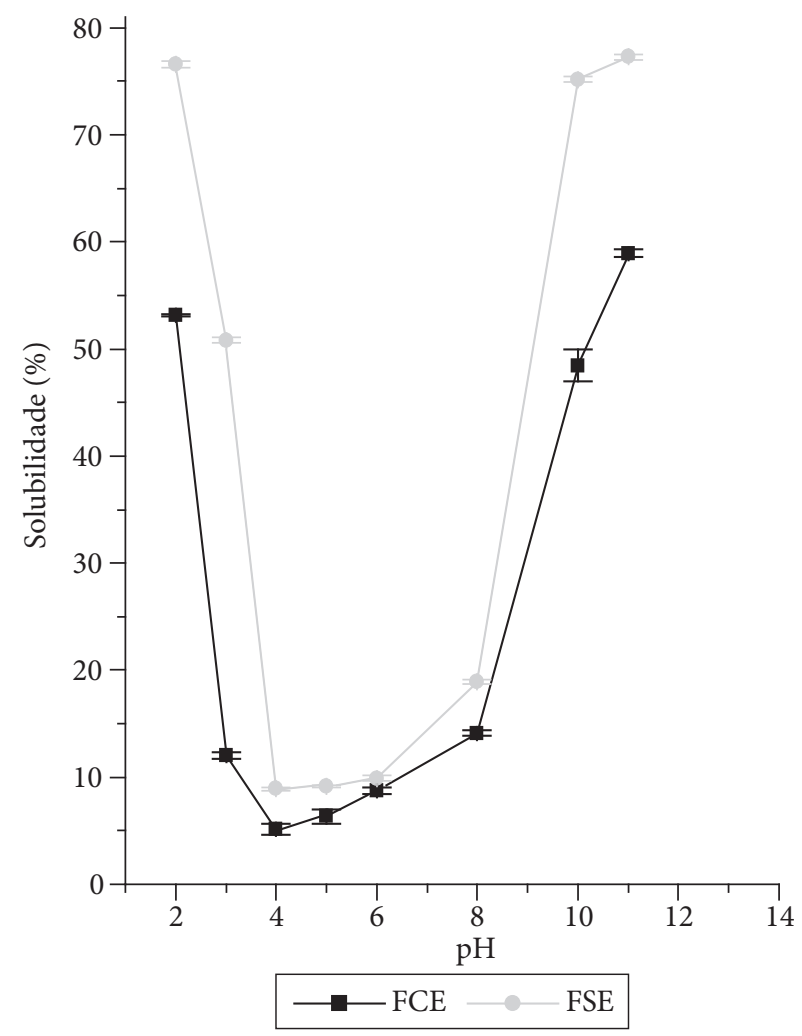

Figura 1. Percentual de proteínas solúveis dos isolados proteicos da faveleira FCE e FSE em níveis de pH 2,0, 3,0, 4,0, 5,0, 6,0, 8,0, 10,0 e 11,0 . 
apresentaram-se estatisticamente diferentes em todos os $\mathrm{pHs}$ estudados. O perfil da solubilidade de uma proteína fornece uma indicação dos tipos de alimentos ou de bebidas em que a proteína poderia ser incorporada.

Perfil de solubilidade semelhante foi encontrado em proteínas de feijão mucuma (ADEBOWALE et al., in press) com menor solubilidade entre pHs 4,0 e 5,0 ( 10\%) e superiores em pHs 2,0 ( $90 \%)$ e 10,0 ( 80\%), respectivamente. O mesmo perfil foi encontrado para as proteínas do amendoim (YU; AHMEDNA; GOKTEPE, 2007), proteínas da macadâmia (BORA; RIBEIRO, 2004), proteína de nozes (PADILLA; ALVAREZ; ALFARO, 1996) e as proteínas de sementes leguminosas chinesas ( $P$. angulares, $P$. calcaratus e D. lablad) (CHAU; CHEUNG, 1998) com menor solubilidade entre os pHs 4,0 e 5,0 (5-10\%) e maior em pHs 10,0 (71,3-88,8\%) e 2,0 (46,1-71,0\%), respectivamente.

\section{Capacidade de absorção de água e óleo}

A capacidade de absorção de água do isolado proteico da amêndoa da variedade de faveleira com espinhos $(1,36 \mathrm{~mL}$ $\mathrm{H}_{2} \mathrm{O} / \mathrm{g}$ proteína) apresentou diferença significativa $(\mathrm{p}<0,05)$ ao encontrado para a faveleira sem espinhos $\left(1,06 \mathrm{~mL} \mathrm{H}_{2} \mathrm{O} / \mathrm{g}\right.$ proteína). Já a capacidade de absorção de óleo dos isolados proteicos da FCE e FSE foram de, respectivamente, 0,99 mL óleo/g proteína e 1,06 mL óleo/g proteína; não apresentaram valores que os diferenciam.

A capacidade de absorção de água que as proteínas ou alimentos proteicos possuem está relacionada com a interação proteína-água, com isso, a maior ou menor afinidade entre proteína e a água está diretamente ligada à textura, viscosidade, geleificação e emulsificação. A hidrofobicidade das proteínas ocupa o principal papel na absorção de óleo e favorece a utilização de alimento proteico na produção de carnes simuladas, linguiças, salsichas, patês, bolos e massas.

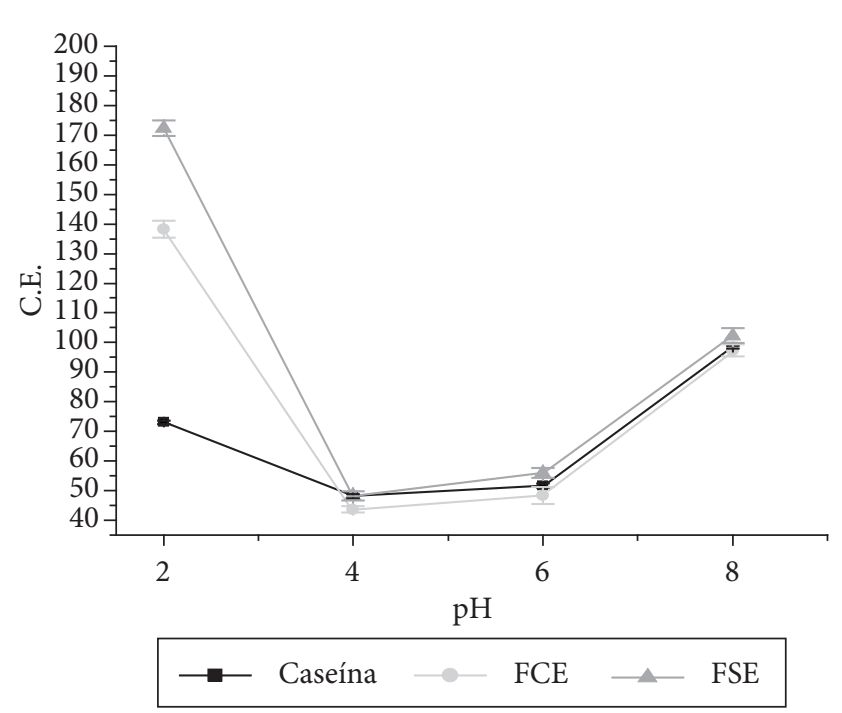

Figura 2. Capacidade de emulsificação dos isolados proteicos da FCE, FSE e da caseína bovina em função dos pHs 2,0, 4,0, 6,0 e 8,0.

\section{Capacidade de emulsificação}

O volume de óleo emulsionado (Figura 2) aumentou acentuadamente no $\mathrm{pH}$ inicial ( $\mathrm{pH} 2,0)$, no qual se verificaram maiores valores $(138,33 \mathrm{~mL}$ óleo/0,1 g proteína da FCE e 172,33 mL óleo/0,1 g proteína da FSE), decresceu no $\mathrm{pH} 4,0$ (43,67 mL óleo/0,1 g proteína da FCE e 48,33 mL óleo/0,1 g proteína da FSE) e voltou a crescer progressivamente nos $\mathrm{pHs}$ 6,0 e 8,0 .

A maior capacidade emulsificante observada foi pelo isolado proteico da FSE em pH 2,0 (172,33 mL óleo/0,1 g proteína) e a menor $(43,67 \mathrm{~mL}$ óleo/0,1 g proteína) foi do isolado proteico da FCE em pH 4,0.

O isolado proteico da variedade da faveleira sem espinhos apresentou diferença entre a variedade da faveleira com espinhos em todos os pHs estudados e comparando com a caseína, esta variedade não diferiu estatisticamente em $\mathrm{pH} 4,0$ e foram significativamente diferentes nos $\mathrm{pHs}$ 2,0, 6,0 e 8,0. Comparando a variedade da faveleira com espinhos com a caseína, observouse que não diferiram em pH 8,0 e apresentaram diferença nos demais $\mathrm{pHs}$ analisados.

\section{Atividade e estabilidade de emulsão}

Como mostram as Figuras 3 e 4, a menor atividade/ estabilidade emulsificante foi observada em pH 4,0, atribuída ao fato das proteínas dos isolados estarem na faixa de $\mathrm{pH}$ isoelétrico, no entanto foi observada uma maior atividade e estabilidade emulsificante em pHs 2,0 e 8,0, em que acontece uma maior solubilidade das proteínas, e o balanço de forças atrativas de Van-der-Waals e forças repulsivas eletrostáticas, influenciam essas propriedades.

A atividade emulsificante da caseína e dos isolados proteicos da faveleira foi dependente do $\mathrm{pH}$ com valores mínimos no pI ( $\mathrm{pH} 4,0)$ para a caseína $(3,59 \%)$ e para as duas variedades, com espinhos $(6,40 \%)$ e sem espinhos $(7,16 \%)$, e maiores em

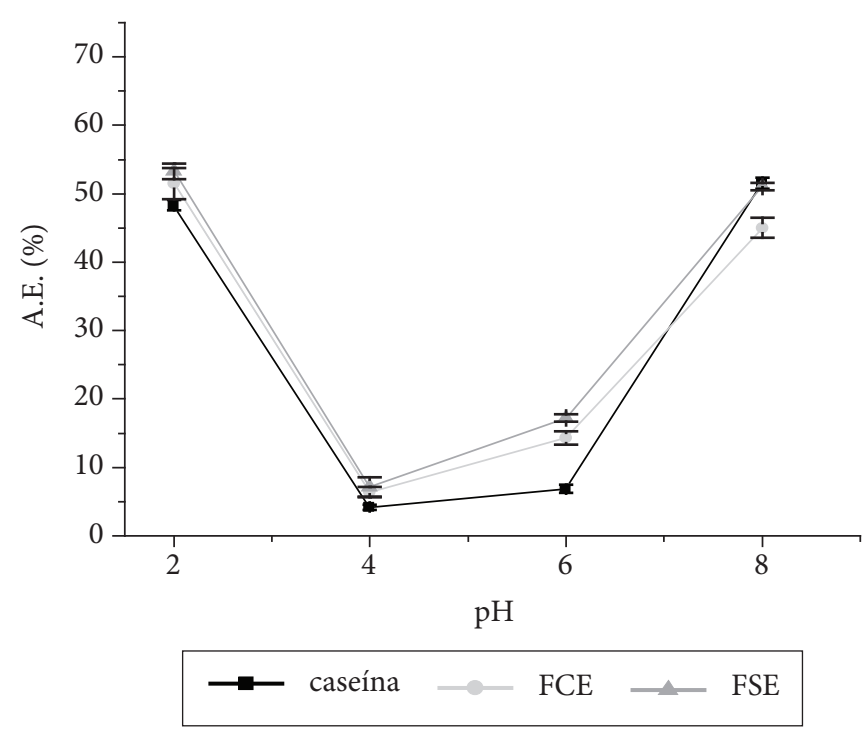

Figura 3. Atividade emulsificante dos isolados proteicos da FCE, FSE e da caseína em pHs 2,0, 4,0, 6,0 e 8,0. 


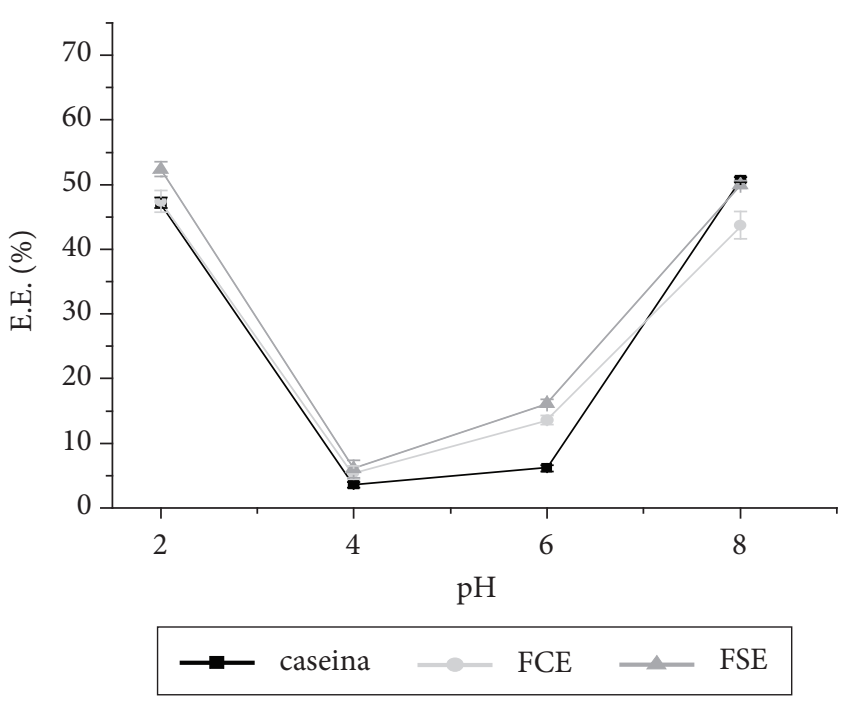

Figura 4. Estabilidade da emulsão dos isolados proteicos da faveleira e da caseína em função do $\mathrm{pH}$.

$\mathrm{pH}$ ácido e alcalino a esse valor de $\mathrm{pH}$. O isolado proteico da faveleira sem espinhos foi superior $(\mathrm{p}<0,05)$ à caseína em pHs 2,0, 4,0 e 6,0 e não apresentou significância em pH 8,0. Já $\mathrm{o}$ isolado proteico da variedade com espinhos foi superior à caseína sem diferir estatisticamente em pHs 2,0 e 4,0, mas em pH 6,0 houve diferença significativa. Em pH 8,0 o isolado proteico da faveleira sem espinhos em relação à caseína apresentou significância.

$\mathrm{O}$ índice de estabilidade do isolado proteico FSE em $\mathrm{pH}$ $2,0(52,40 \%)$ foi superior $(\mathrm{p}<0,05)$ ao da caseína $(47,16 \%)$, como também ao ido solado proteico FCE $(47,41 \%)$. Em pH 4,0 , o isolado proteico FSE (6,03\%) apresentou índice superior $(\mathrm{p}<0,05)$ à caseína e não apresentou diferença significativa comparado ao isolado FCE. O índice de estabilidade, em pH 6,0, do isolado FSE $(16,19 \%)$ foi superior $(\mathrm{p}<0,05)$ ao do isolado FCE $(13,60 \%)$ e ao da caseína (6,13\%). Em pH 8,0, a caseína $(50,77 \%)$ apresentou índice superior $(\mathrm{p}<0,05)$ ao isolado FCE $(43,72 \%)$ e não diferiu estatisticamente com ao isolado FSE $(50,00 \%)$.

\section{Conclusões}

$\mathrm{O}$ isolado proteico das amêndoas de faveleira apresentou potencial de utilização em alimentos elaborados, inclusive em produtos que exijam alta solubilidade dos ingredientes, em produtos com alta performance de emulsificação de óleo e em sistemas alimentícios influenciando na textura e no flavor dos alimentos. Pesquisas posteriores serão necessárias no sentido de relacionar a funcionalidade deste isolado com o desempenho em sistemas de alimentos específicos e de estudar o aspecto da viabilidade econômica da sua produção.

\section{Agradecimentos}

Ao CNPq pelo apoio através da bolsa concedida à discente Mônica Tejo Cavalcanti.

\section{Referências bibliográficas}

ADEBOWALE, Y. A. et al. Isolation, fractionation and characterisation of proteins from Mucuna bean. Food Chemistry. (in press). Disponível em:http://www.sciencedirect.com>

Association of Official Analytical Chemists - AOAC. Official Methods of Analysis. Washington, 2000. 1018 p.

BARCELOS, M. F. P.; VILAS BOAS, E. V. B.; LIMA, M. A. C. Aspectos nutricionais de brotos de soja e de milho combinados. Ciências Agrotécnicas, v. 26, n. 4, p. 817-825, 2002.

BORA, P. S.; RIBEIRO, D. Note: Influence of $\mathrm{pH}$ on the Extraction Yield and Functional Properties of Macadamia (Macadamia Integrofolia) Protein Isolates. Food Science and Technology International, v. 10, n. 4, p. 263-267, 2004.

BRAGA, R. Plantas do Nordeste, especialmente do Ceará. 2 ed. [S.1]: Imprensa Oficial do Ceará, 1960. 540 p.

CHAU, C. F.; CHEUNG, P. C. K. Functional properties of flours prepared from three Chinese indigenous legume seeds. Food Chemistry, v. 61, n. 4, p. 429-433, 1998.

DENCH, J. E.; RIVAS, N. R.; CAYGILL, J. C. Selected functional properties of sesame (Sesamum indicum L.) flour and two protein isolates. Journal of the Science of Food and Agriculture, v. 32, n. 6, p. 557-564, 1981.

DUQUE, J. G. O Nordeste e as lavouras xerófilas. 3 ed. Mossoró, RN: ESAM - Fundação Guimarães Duque, 1980. p. 337.

EL NASRI, N. A.; EL TINAY, A. H. Functional properties of fenugreek (Trigonella foenum graecum) protein concentrate. Food Chemistry, v. 103, p. 582-589, 2007.

GORNALL, A. G.; BORDAWILL, C. S.; DAVID, M. M. The determination of protein by the biuret reaction. Journal Biology Chemistry, v. 177, p. 751-780, 1949.

HUNG, S. C.; ZAYAS, J. F. Emulsifying capacity and emulsion stability of milk proteins and corn germ protein flour. Journal and Food Science, v. 56, n. 5, p. 1216-1219, 1991.

KATO, A. et al. Determination of emulsifying properties of some proteins by conductivity measurements. Journal of Food Science, v. 50, n. 1, p. 50-62, 1985.

KHALIL, M.; RAGAB, M.; ABD EL-AAL, M. H. Foaming properties of oilseed proteins. Die Nahrung, v. 29, n. 2, p. 201-207, 1985.

LIN, C. S.; ZAYAS, J. F. Functionality of defatted corn germ protein in a model system: fat binding capacity and water retention. Journal of Food Science, v. 52, n. 5, p. 1308-1311, 1987.

McWATTERS, K. H.; HOLMES, M. R. Influence of moist heat on solubility and emulsification properties of soy and peanut flours. Journal of Food Science, v. 44, n. 3, p. 774-776, 1979.

MOREIRA, J. A. N. et al. Ocorrência de faveleiro sem espinho no Estado do Ceará, Brasil. Ciência Agronômica, v. 4, n. 1-2, p. 51-55, dez. 1974.

OLIVEIRA, J. T. A. et al. Composition and nutritional properties of seeds from Pachira aquatica Aubl, Sterculia striata StHil et Naud and Terminalia catappa Linn. Food Chemistry, v. 70, p. 185-191, 2000 .

ORDONEZ, J. A. et al. Componentes dos Alimentos e Processos Tecnologia de Alimento. Porto Alegre: Editora Artmed, 2005.

PADILlA, F. C.; AlVAREZ, M. T.; AlFARO, M. J. Functional properties of barinas nut flour (Caryodendron orinocense Karst., Euphorbiaceae) compared to those of soybean. Food Chemisrry, v. 57, n. 2, p. 191-196, 1996. 
QUEIROGA NETO, V. et al. Functional properties of raw and heat processed cashew nut (Anacardium occidentale, L.) kernel protein isolates. Die Nahrung, v. 45, n. 4, p. 258-262, 2001.

QUINN, J. R.; PATON, D. Method for water hydration capacity of plant protein materials. Food World/Page, v. 26, n. 6, p. 291-293, 1979.

RAMOS, C. M. P.; BORA, P. S. B. Extraction and characteristics of Brazil nut (Bertholletia excelsa HBK) globulin. Food Science Technology International, v. 9, n. 4, p. 265-270, 2003.

SANTOS, J. C. O. et al. Thermoanalytical study of faveleira seeds (Cnidoscolus quercifolius). Journal of Thermal Analysis and Calorimetry, v. 79, n. 2, p. 271-275, 2005.

SOUZA, M. L.; MENEZES, H. C. Processamentos de amêndoa e torta de castanha-do-brasil e farinha de mandioca: parâmetros de qualidade. Ciências e Tecnologia de Alimentos, v. 24, n. 1, p. 120-128, 2004.

SPSS Inc. 11.0 for Windows [Computer program]; LEAD Technologies. Chicago, 2001.

WEEB, N. B.; IVEY, F. J.; CRIC, H. B. The measurement of emulsifying capacity by electrical resistence. Journal of Food Science, v. 35, n. 2, p. 501-504, 1970.

YASUMATSU, K.; SAWADA, K.; MORITAKA, S. Whippings and emulsifying properties of soy bean products. Agricultural and Biological Chemistry, v. 35, n. 5, p. 719-727, 1972.

YU, J.; AHMENDNA, M.; GOKTEPE, I. Peanut protein concentrate: Production and functional properties as affected by processing. Food Chemistry, v. 103, p. 121-129, 2007. 